\title{
Folate Status in Egypt
}

\author{
Afaf A. Tawfik ${ }^{1}$, Emily T. Hanna ${ }^{2}$, Shadia A. Freig ${ }^{2}$ \\ ${ }^{I}$ (Field studies and research Dept., National Nutrition Institute, Cairo, Egypt.) \\ ${ }_{2}^{2}$ (Nutrition Biochemistry and Metabolism Dept., National Nutrition Institute, Cairo, Egypt.)
}

\begin{abstract}
The aim of this work was to assess folate status among Egyptian population as baseline data for iron/folic acid flour fortification program. Blood samples (1910) were collected for three target groups: mothers, adolescents (12-18yr) and children (6-<12yr), drawn from nine governorates representing four regions; Metropolitan (greater Cairo), Costal (Alexandria \&Suez), Lower Egypt (Kafr Elshaik; Sharkia; and Behaira), and Upper Egypt (Bani-suif; Aswan; and Qena). Serum folate was determined using HPLC, and folate deficiency was defined at serum level $<10 \mathrm{nmol} / \mathrm{L}$ according to WHO. Overall mean serum folate level was $13.4 \mathrm{nmol} / \mathrm{L}$ and folate deficiency identified among $13.7 \%$ of whole sample. Mothers and children were slightly more vulnerable for folate deficiency (14.7-14.9\%) than adolescents (12.6\%). Folate deficiency was significantly higher in Lower Egypt (23.1\%) than Upper Egypt (14.7\%), Metropolitan (7.4\%) and Costal region (3.9\%).
\end{abstract}

Keywords: Mothers, adolescents, children, fortification, serum folate.

\section{Introduction}

WHO Technical Consultation on folate and vitamin B12 deficiencies reported that there is strong evidence that folate deficiency causes megaloblastic anemia. In regions where folate deficiency is more common during pregnancy and lactation, a few studies have associated megaloblastic anemia with prolonged lactation and multiple pregnancies. On the other hand, there is evidence of an inverse association between blood folate concentrations and risk of low birth weight and increased risk of neural tube defects (NTD). Moreover, serum/plasma folate concentrations affect cognitive function in children than in adults, and some studies have reported lower scores in schoolchildren with low folate status [1].

Poor folate status in vulnerable women of childbearing age increases the risk of neural tube birth defects, so the critical time for the contribution of folic acid is several months before conception since neural tube closure occurs during the first weeks of life [2].

A healthy balanced diet provides the best basis for optimal pregnancy outcome, lactation performance, and complementary feeding. However, supplements or fortified foods may be needed to cover the high requirements especially of critical vitamins such as vitamin D and folic acid and to correct unfavorable dietary patterns in women or to adapt foods to the needs of young children [3].

[4] reviewed the impact of folic acid fortification of flour on the prevalence of NTD in Chile, Argentina, Brazil, Canada, Costa Rica, Iran, Jordan, South Africa and the USA. They concluded that fortification of flour with folic acid has had a major impact on NTD in all countries. Chile showed a $55 \%$ reduction in NTD prevalence between 1999 and 2009.

Flour fortification has been widely implemented in countries of the Eastern Mediterranean, Middle East and North Africa region. The WHO Regional Office for the Eastern Mediterranean with support from the UNICEF and the Micronutrient Initiative (MI) launched an initiative in 1999 which subsequently led to nearly all the countries in the region fortifying wheat flour with at least iron and folic acid by 2009 .

The Kingdom of Bahrain reports significant declines in anemia among pregnant women and in the prevalence of neural tube birth defects. Anemia among pregnant women dropped from 40\% in 1996 to 23\% in 2012. The prevalence of NTD declined from 2.6 to 0.9 per 1000 live births [5].

The reduction in spina bifida rates in Oman could be linked to the start of flour fortification with iron and folate in 1996 but not the folate supplementation programme of pregnant women in 1990 [6].

Iron/folic acid fortification program for wheat flour (82\% extraction) used for Baladi bread consumed by Egyptians started for gradual implementation since 2008, as a long-term strategy for prevention and control of iron deficiency anemia. Therefore, data on folate status assessment among Egyptians is an essential component for monitoring and evaluation of the fortification program outcome.

\section{Methodology}

The survey was conducted among three target population groups: women of reproductive age (20 $49.9 \mathrm{y}$ ), adolescents $12-18 \mathrm{y}$ and children $6-<12 \mathrm{y}$. They were covered from a stratified community cluster 
sample technique for household (HH). The estimated total number of households was about 1910 to be collected from 4 clusters (30 households each).

2.1. Sample selection:

Nine governorates were selected randomly to represent four regions; Metropolitan (greater Cairo), Costal (Alexandria and Suez), Lower Egypt (Kafr Elshaik; Sharkia; and Behaira), and Upper Egypt (Bani-suif; Aswan; and Qena). Urban and rural areas from Lower \& Upper regions were considered.

The selection of villages and cities was based on using proportionate population sampling (PPS) technique.

The selection of target population was based on mother and children at HH. Households' children 6-18yr was selected from the nearest schools (primary, preparatory / secondary) with purposely selection of adolescent females for their vulnerability to folic acid deficiency.

The study was approved by the Ethical committee of the National Nutrition Institute and confirmed by the General Organization of Hospitals and Institutes and the Ministry of Health.

Written, informed consent was obtained from the mothers' each child participating in the study.

1.2. Blood sample collection and preparation:

Venous blood samples were taken into tubes. Serum was separated by centrifugation of samples at $3000 \mathrm{rpm}$, and $860 \mu \mathrm{L}$ serum were stored in Eppendorf containing $40 \mathrm{mg}$ ascorbic acid under light protection at $-20^{\circ} \mathrm{C}$ until analysis.

\subsection{Folate determination:}

Frozen serum samples were thawed and mixed with $0.1 \mathrm{ml}$ of $60 \%$ perchloric acid, centrifuged at 4000 $\mathrm{rpm}$ for $20 \mathrm{~min}$. The deproteinized samples were analyzed immediately. A volume of $100 \mathrm{ul}$ of the supernatant was injected at a flow rate of $1.5 \mathrm{ml} / \mathrm{min}$ into the High Performance Liquid Chromatography (HPLC) with fluorescence detector adjusted at the excitation wavelength $295 \mathrm{~nm}$ and the emission wavelength $365 \mathrm{~nm}$, according to the method described by [7] to measure 5- methyltetrahydrofolate in serum. The column used was spherisorb $25 \mathrm{~cm} \mathrm{X} 4.6 \mathrm{~mm}$ internal diameter. The mobile phase contained $8 \%$ acetonitrile in $0.033 \mathrm{~m}$ orthophosphoric acid, and the PH was adjusted to 2.3 with solid sodium hydroxide. Standard solutions for the calibration curve were prepared from $(5 \mathrm{ng} / \mathrm{ml}$ to $20 \mathrm{ng} / \mathrm{ml}) 5$-methyltetrahydrofolate in $1 \%$ ascorbic acid solution and stored in aliquots at $-20^{\circ} \mathrm{C}$.

\subsection{Folate indicators}

The concentration for defining folate deficiencies was based on metabolic indicators at $<10 \mathrm{nmol} / \mathrm{L}$ (4 $\mathrm{ng} / \mathrm{mL}$ ) for serum folate [1].

\section{Results and discussion}

The survey study was conducted among sample of 1910 subjects (TABLE 1) to include three main target groups expected to be vulnerable for folate deficiency. Mothers accounted for $30.3 \%$ of whole sample, adolescents (12-18 yr, male \& female) $51.5 \%$, and children $(6-<12 \mathrm{yr}$, male \& female) as $18.2 \%$. Four geographic regions were considered Metropolitan (Great Cairo capital city), Costal region, Lower \& Upper Egypt regions which actually include both rural and urban residence area.

Table (1): Distribution of Surveyed Samples for Folate Analysis According to Geographic Region, Residence Area and Gender

\begin{tabular}{|c|c|c|c|c|}
\hline Target & Mother & $\begin{array}{l}\text { Children } \\
(6-<12 \text { yr })\end{array}$ & $\begin{array}{l}\text { Adolescents } \\
(12-18 \text { yr })\end{array}$ & Total \\
\hline Total: No & 579 & 348 & 983 & 1910 \\
\hline$(\%)$ & 30.3 & 18.2 & 51.5 & 100.0 \\
\hline \multicolumn{5}{|c|}{ Geographic Region } \\
\hline Metropolitan & 67 & 68 & 122 & 257 \\
\hline Costal & 156 & 118 & 133 & 407 \\
\hline Lower Egypt & 182 & 107 & 217 & 506 \\
\hline Upper Egypt & 174 & 55 & 511 & 740 \\
\hline \multicolumn{5}{|c|}{ Residence Area } \\
\hline Urban & 312 & 210 & 581 & 1103 \\
\hline Rural & 267 & 138 & 402 & 807 \\
\hline \multicolumn{5}{|c|}{ Gender } \\
\hline Male & - & 172 & 106 & 278 \\
\hline Female & 579 & 176 & 877 & 1632 \\
\hline
\end{tabular}

The assessment was based on determination of serum folate from blood samples drawn from the target subjects. Mean serum folate values for the target groups were almost similar with an overall mean value of 13.4 
nmol/L (TABLE 2), meanwhile the median values were very close to mean values indicating serum folate values fit normal distribution.

Table (2): Serum Folate Values (nmol/L) and Folate Deficiency among Target Groups

\begin{tabular}{|c|c|c|c|c|c|}
\hline \multirow[t]{2}{*}{ Target group } & \multirow[b]{2}{*}{ No. } & \multicolumn{2}{|c|}{ Serum folate values $(\mathrm{nmol} / \mathrm{L})$} & \multicolumn{2}{|c|}{$\begin{array}{c}\text { Folate deficient } \\
(<10 \mathrm{nmol} / \mathrm{L})\end{array}$} \\
\hline & & Mean $\pm($ SD $)$ & Median & No. & $\%$ \\
\hline Mothers & 579 & $13.1 \pm 3.2$ & 12.8 & 85 & 14.7 \\
\hline Children & 348 & $13.8 \pm 3.4$ & 13.7 & 52 & 14.9 \\
\hline Total & 1910 & $13.4 \pm 3.3$ & 13.7 & 261 & 13.7 \\
\hline
\end{tabular}

WHO consultation has arrived at consensus for cutoffs levels for folate that should be used for assessing the nutritional status of populations. It was based on the plasma vitamin concentrations below which plasma metabolites become elevated. In addition, these cutoffs are consistent with the recommended intakes of folate, in which blood vitamin concentrations were used to determine estimated average requirements. The concentrations suggested for defining folate deficiencies based on metabolic indicators were $<10 \mathrm{nmol} / \mathrm{L}$ $(4 \mathrm{ng} / \mathrm{mL})$ for serum folate [1]. Results showed that the overall folate deficiency accounted for $13.7 \%$ of the whole population; mother and children recorded slightly higher percentages $(14.7 \%$ and $14.9 \%$, respectively) than adolescents (12.6\%). Results of serum folate level and prevalence of folate deficiency in Egypt are comparable with Iran data. Implementation of mandatory flour fortification with folic acid in Iran led to that mean serum folate level significantly increased from 13.6 to $18.1 \mathrm{nmol} / \mathrm{L}$, and folate deficiency decreased from 14.3 to $2.3 \%$ [8]. [9] established a baseline of RBC folate, folate consumption and supplement use in Aboriginal and non-Aboriginal West Australians groups prior to the introduction of a universal program of folate fortification. They identified $10 \%$ of Aboriginal women and non-Aboriginal women participants with low folate concentrations.

With respect to factors affecting folate status, three variables were considered: gender, geographic regions and residence area. "Fig." (1) showed that young male children $(6-<12 \mathrm{yr})$ recorded higher prevalence than females $(18.6 \%$ Vs $11.4 \%)$, but the difference was not statically significant $(\mathrm{p}<0.06)$. At adolescent age opposite picture was observed where prevalence among females was more than males (12.9\% Vs $10.4 \%)$, however still the difference was not significant $(\mathrm{P}<0.075)$. Using a large hospital population, pediatric reference ranges were obtained for folic acid [10]. The range for subjects aged 1 to 12 years averaged 5.7 to $31.3 \mathrm{nmol} / \mathrm{L}$ for female subjects and 4.5 to $27.0 \mathrm{nmol} / \mathrm{L}$ for male subjects. There was a significant decrease in folic acid concentrations after 13 years, the upper limit being $16.5 \mathrm{nmol} / \mathrm{L}$ in female and $19.9 \mathrm{nmol} / \mathrm{L}$ in male. [11] measured folate level among 524 children (275 boys and 249 girls) aged 6-15 years old from different socioeconomic status in Northern Greece. Six percent of subjects were found to have low folate levels (laboratory minimal reference value $=3.4 \mathrm{ng} / \mathrm{mL}$ ). Folate was markedly decreased as age was increased. On the other hand, among US adolescents, fortification substantially improved serum folate concentrations and attenuated the age related decrease in serum folate concentrations, with a great impact on females than males. Folic acid fortification was associated with $16 \%$ higher mean serum folate concentrations. Furthermore, fortification resulted in dietary intakes of folate that approached or exceeded the RDA. Dietary intake was strongly and positively associated with change in serum folic acid concentration $(1.01 \mathrm{nmol} / \mathrm{L}$ increase in serum folic acid concentration for every $100 \mathrm{ug} /$ day increase in folate intake) [12].

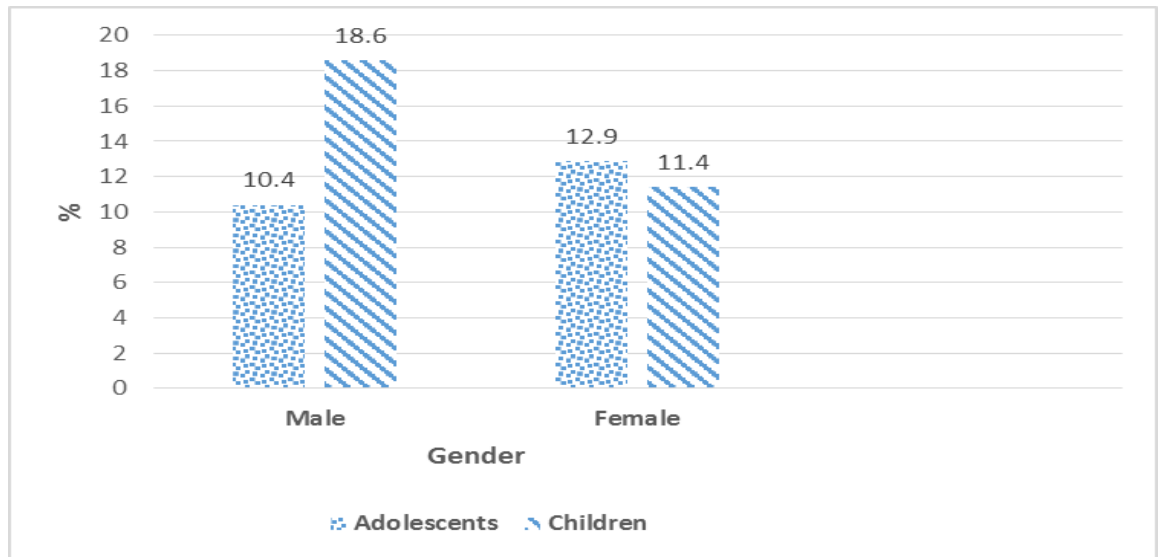

Figure (1): folate deficiency among adolescents and children by gender 
Folate status among four geographic regions "Fig." (2) showed that two regions (Lower and Upper Egypt) recorded significantly $(\mathrm{P}<0.000)$ higher percentages for folate deficiency than other two regions (Metropolitan and Costal). Folate deficiency among all target groups in Lower region recorded higher values $(18.9 \%-28.8 \%)$ with an average of $23.1 \%$. Upper Egypt region, the prevalence values among target groups (range $12.1 \%-14.9 \%$ ) with average of $14.7 \%$. Metropolitan, and Costal regions recorded low percent folate deficiency among all target groups with an average percent of $7.4 \%$ and $3.9 \%$, respectively. The primary cause of folate deficiency is low intake of rich sources of vitamin, such as legumes and green leafy vegetables. Most developing countries have few, common sources of folic acid, unlike many developed countries, which have folic acid available from ready-to-eat cereals and supplements. Estimates showed that in United States and Canada, the additional intake of about 100 to 150 microgram/day of folic acid through food fortification has been effective in reducing the prevalence of NTD and increasing blood folate concentration in both countries [13].

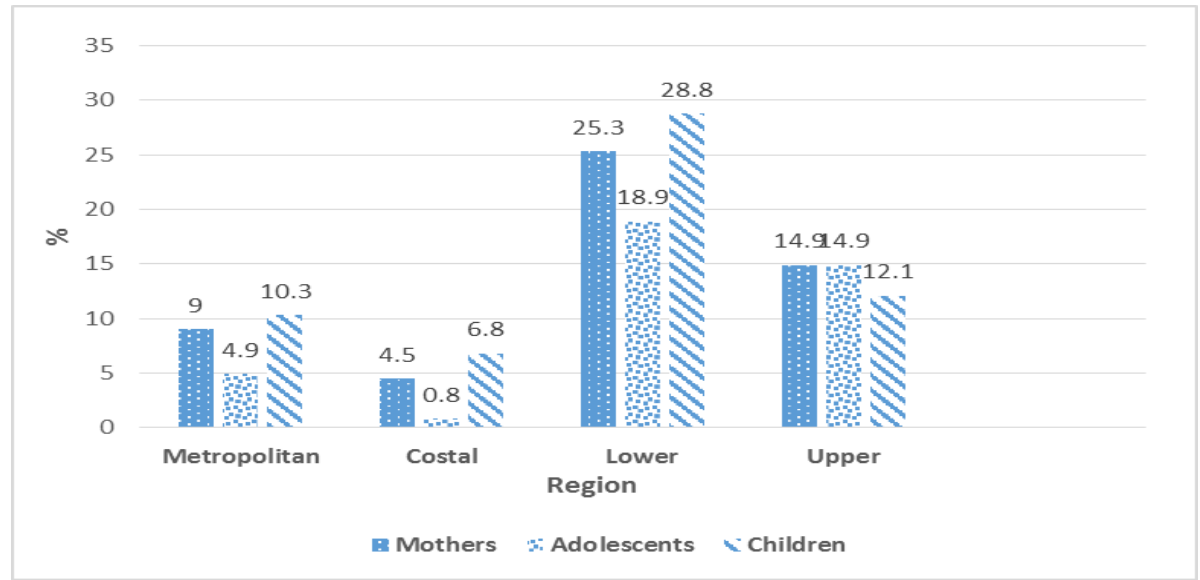

Figure (2): folate deficiency among target groups by region

Residence area as factor was considered and "Fig." (3) presented folate deficiency according to urban and rural area of residence. No significant difference was found among target groups between urban and rural areas.

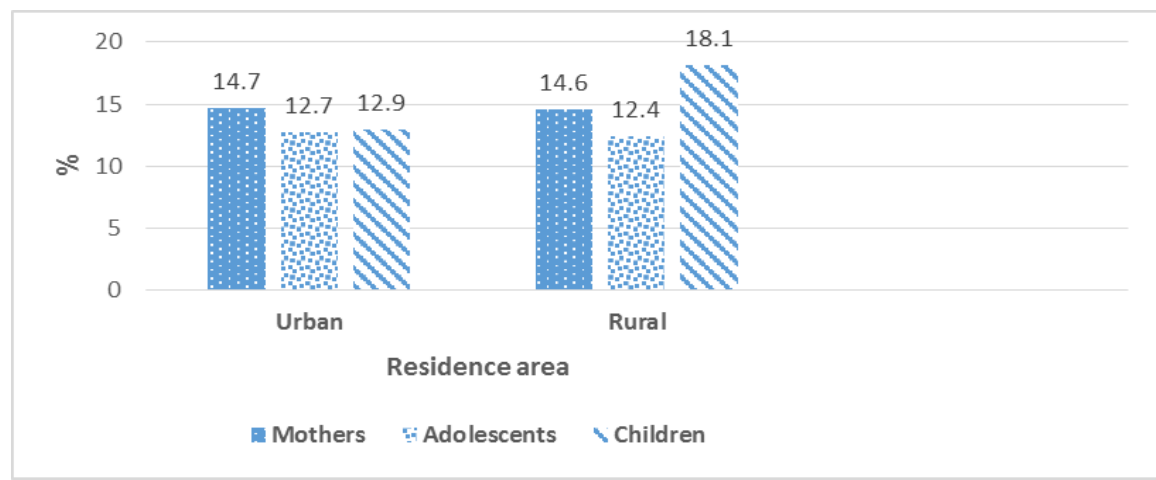

Figure (3): folate deficiency among target groups by residence area.

\section{Conclusion}

The study furnishes a baseline data on serum folate levels and the prevalence of folate deficiency among three target population groups and the main factors affecting folate deficiency.

Nutritional education is essential to achieve a good impact of food fortification programs, promoting simultaneously the composition of iron absorption enhancers (such as ascorbic acid and red meat) and avoiding iron inhibitors (tea and coffee, for example). Strengthening other strategies to complement the fortification program; such as supplementation program for vulnerable groups as well as screening program and dietary diversification.

Regulatory monitoring for folate status is required among vulnerable groups for prevention and control of folate deficiency with the risk of NTD as well as the risk of megaloblastic anemia in pregnancy and lactation. 


\section{References}

[1]. WHO, Conclusions of a WHO Technical Consultation on folate and vitamin B12 deficiencies, Food Nutr. Bull., 29 (2 Suppl.), 2008, S238-44.

[2]. A. Brito, E. Hertrampf, M. Olivares, D. Gaitán, H. Sánchez, L.H. Allen and R. Uauy, Folate, vitamin B12 and human health, Rev Med Chil., 140(11), 2012, 1464-75.

[3]. I. Elmadfa, and A. L. Meyer, Vitamins for the first 1000 days: preparing for life, Int. J. Vitam. Nutr. Res., 82 (5), $2012,342-7$.

[4]. C. Castillo-Lancellotti, J. A. Tur, and R. Uauy, Impact of folic acid fortification of flour on neural tube defects: a systematic review, Public Health Nutr., 16 (5), 2013, 901-11.

[5]. FFI Flour Fortification Initiative Newsletter December 2012

[6]. D. Alasfoor, M.K. Elsayed, A.J. Mohammed, Spina bifida and birth outcome before and after fortification of flour with iron and folic acid in Oman. East Mediterr Health J., 16(5) 2010, 533-8.

[7]. R.J. Leeming, A. Pollock, L. J. Melville and C. G. B. Hamon, Measurement of 5-Methyltetrahydrofolic Acid in Man by HighPerformance Liquid Chromatography, Metabolism, 39 (9), 1990, 902-904.

[8]. Z. Abdollahi, I. Elmadfa, A. Djazayery, M.J. Golalipour, J. Sadighi, F. Salehi, and S. Sadeghian Sharif, Efficacy of flour fortification with folic acid in women of childbearing age in Iran, Ann Nutr Metab.; 58 (3), 2011, 188-96.

[9]. S.J. Maxwell, K.J. Brameld, C. Bower, H. D'Antoine, S. Hickling, J. Marley, and P. O'Leary, Baseline investigations of folate status in Aboriginal and non-Aboriginal West Australians prior to the introduction of mandatory fortification, Aust $\mathrm{N} Z \mathrm{Z}$ Obstet Gynaecol. 53(1), 2013, 26-31.

[10]. J.M. Hicks, J. Cook, I. D. Godwin, and S. J. Soldin, Vitamin B12 and folate. Pediatric reference ranges. Arch Pathol Lab Med; 117, 1993, 704-6.

[11]. D. Papandreou, I. Mavromichalis, A. Makedou, I. Rousso, and M. Arvanitidou, Total serum homocysteine, folate and vitamin B12 in a Greek school age population, Clin. Nutr. 25(5), 2006, 797-802.

[12]. D. A. Enquobahrie, H. A. Feldman, D. H. Hoelscher, L. M. Steffen, L. S. Webber, M. M. Zive, E. B. Rimm, M. J. Stampfer, and S. K. Osganian, Serum homocysteine and folate concentrations among a US cohort of adolescents before and after folic acid fortification, Public Health Nutr. 15(10), 2012, 1818-26.

[13]. R. J. Berry, L. Bailey, J. Mulinare, C. Bower, and Folic Acid Working Group, Fortification of flour with folic acid. Food Nutr. Bull. Mar; 31(1 Suppl), 2010, S22-35. 